
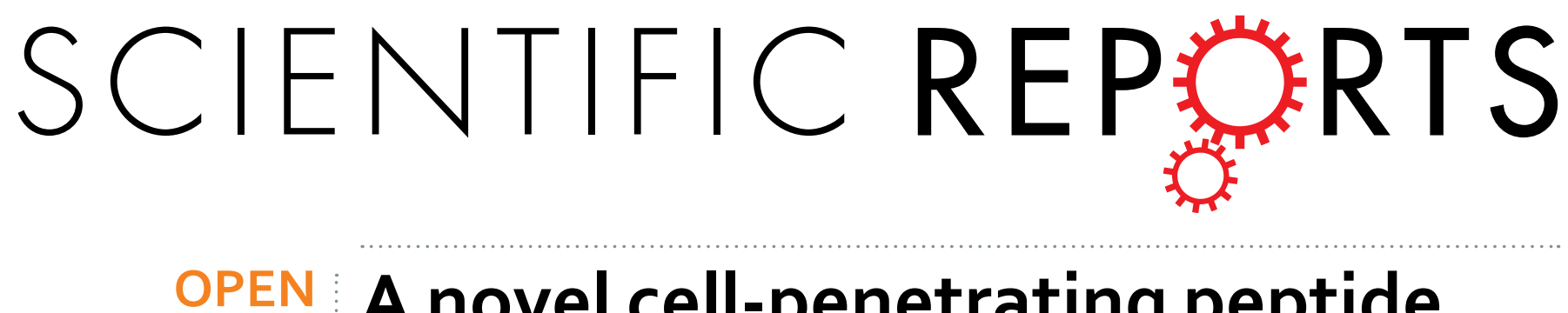

\title{
A novel cell-penetrating peptide suppresses breast tumorigenesis by inhibiting $\beta$-catenin/LEF-1 signaling
}

Received: 23 September 2015

Accepted: 30 November 2015

Published: 11 January 2016
Tsung-Hua Hsieh ${ }^{1,2,3}$, Chia-Yi Hsu ${ }^{5}$, Cheng-Fang Tsai ${ }^{5}$, Chien-Chih Chiu ${ }^{2}$, Shih-Shin Liang ${ }^{2}$, Tsu-Nai Wang ${ }^{2}$, Po-Lin Kuo ${ }^{2}$, Cheng-Yu Long ${ }^{1}$ \& Eing-Mei Tsai ${ }^{1,2,3,4,5}$

The inhibition of $\beta$-catenin/LEF-1 signaling is an emerging strategy in cancer therapy. However, clinical targeted treatment of the $\beta$-catenin/LEF- 1 complex remains relatively ineffective. Therefore, development of specific molecular targets is a key approach for identifying new cancer therapeutics. Thus, we attempted to synthesize a peptide (TAT-NLS-BLBD-6) that could interfere with the interaction of $\beta$-catenin and LEF- 1 at nuclei in human breast cancer cells. TAT-NLS-BLBD- 6 directly interacted with $\beta$-catenin and inhibited breast cancer cell growth, invasion, migration, and colony formation as well as increased arrest of sub-G1 phase and apoptosis; it also suppressed breast tumor growth in nude mouse and zebrafish xenotransplantation models, showed no signs of toxicity, and did not affect body weight. Furthermore, the human global gene expression profiles and Ingenuity Pathway Analysis software showed that the TAT-NLS-BLBD-6 downstream target genes were associated with the HER-2 and IL-9 signaling pathways. TAT-NLS-BLBD- 6 commonly down-regulated 27 candidate genes in MCF-7 and MDA-MB-231 cells, which are concurrent with Wnt downstream target genes in human breast cancer. Our study suggests that TAT-NLS-BLBD- 6 is a promising drug candidate for the development of effective therapeutics specific for Wnt// $\beta$-catenin signaling inhibition.

Breast cancer is a common malignancy and ranks as the fourth leading cause of cancer mortality in women worldwide ${ }^{1}$. Early study revealed that mutation of mammary ducts and lobules is the main contributory factor. There are many factors that affect mutation including genetics ${ }^{2}$, lifestyle ${ }^{3}$, viral infections ${ }^{4}$, tobacco use ${ }^{5}$, and environment ${ }^{6}$. In current therapy, breast cancer patients are mainly treated with surgery, chemotherapy, and a combination regimen ${ }^{7}$. Interestingly, new drug development has been enhanced by advancements in targeted gene therapy ${ }^{8}$. Targeted gene therapy includes the successful application of monoclonal antibodies (Her $2 /$ neu $)^{9}$ and small peptides. The lack of toxicity and immunogenicity as well as stable cell penetration make small peptides a promising avenue for therapeutic development ${ }^{10}$. Among these targets, catenin beta-1/lymphoid enhancer factor-1 ( $\beta$-catenin/LEF-1) is a very important complex in new drug development for small peptides.

The $\beta$-catenin/LEF- 1 complex is a nuclear response transcription factor and plays an important role in the $\mathrm{Wnt} /$ wingless signaling pathway ${ }^{11}$. The $\mathrm{Wnt} /$ wingless pathway regulates many tumorigenic processes including cell growth ${ }^{12}$, invasion ${ }^{13}$, migration ${ }^{14}$, colony formation, and xenografting in human cancer ${ }^{15}$. When the Wnt receptor complex is unbound, $\beta$-catenin forms a complex with adenomatous polyposis coli (APC), axin, and glycogen synthase kinase $3 \mathrm{~b}$ (GSK3b), which then undergoes ubiquitin-mediated degradation in the cytoplasm. Otherwise, upon Wnt binding to the receptor complex, $\beta$-catenin translocates to the nucleus and binds with the LEF-1/TCF co-transfection factor. It has been reported that the first 76 amino acids of LEF-1 are sufficient for the interaction with $\beta$-catenin ${ }^{11}$. In addition, early study found that $\beta$-catenin activates downstream target genes including $\mathrm{BMP} 4^{16}, \mathrm{MYC}^{17}$, and cyclin $\mathrm{D} 1^{18}$, which play important oncogenic roles to promote breast cancer migration, invasion, and tumorigenesis. Therefore, suppressing the $\beta$-catenin/LEF- 1 signaling pathway is an important direction in new drug development.

${ }^{1}$ Department of Obstetrics and Gynecology, Kaohsiung Medical University Hospital, Kaohsiung Medical University, Kaohsiung, Taiwan. ${ }^{2}$ Research Center for Environmental Medicine, Kaohsiung Medical University, Kaohsiung, Taiwan. ${ }^{3}$ Center for Stem Cell Research, Kaohsiung Medical University, Kaohsiung, Taiwan. ${ }^{4}$ Center for Infectious Disease and Cancer Research, Kaohsiung Medical University, Kaohsiung, Taiwan. ${ }^{5}$ Graduate Institute of Medicine, College of Medicine, Kaohsiung Medical University, Kaohsiung, Taiwan. Correspondence and requests for materials should be addressed to E.-M.T. (email: tsaieing@yahoo.com) 
In the current study, we synthesized a small peptide to block the interaction between $\beta$-catenin and LEF- 1 . The effects on tumorigenesis and the downstream target gene profile in human breast cancer were investigated in vitro and in vivo. This novel small peptide may be a candidate in future approaches for human breast cancer therapy.

\section{Results}

TAT-NLS-BLBD-6 inhibits the growth of breast cancer cells. First, we synthesized successive short peptides of the $\beta$-catenin/LEF- 1 binding domain ${ }^{11}$ (BLBD), transactivator of transcription (TAT, YGRKKRRQRRR), and nuclear localization signal (NLS, RKRRK) protein to form a fusion peptide (Fig. 1a). BLBD peptides were derived from the first 76 amino acids of LEF-1, which are sufficient for the interaction with $\beta$-catenin. TAT is a cell-penetrating peptide from the human immunodeficiency virus, and it can deliver proteins, DNA, RNA, and nanoparticles into the cytoplasm in a short time with extremely high efficiency ${ }^{19,20}$. However, because stabilized $\beta$-catenin translocates into the nucleus to affect TCF-4/LEF-1 binding to Wnt target genes ${ }^{21}$, we synthesized TAT-NLS fusion peptides derived from LEF- 1 to analyze their effects on $\beta$-catenin-mediated signaling in the nuclei of breast cancer cells. We chemically synthesized six peptides with a variable region of the $\beta$-catenin/LEF- 1 binding domain and one mutated version of BLBD- 6 to find the capacity of these peptides to suppress cancer cell growth (Fig. 1a). A growth assay was used to screen the small peptides for their ability to suppress cancer cell growth. The results indicated that two synthetic peptides (TAT-NLS-BLBD-3 and -6) inhibited the growth of MCF-7 and MDA-MB-231 cells (Fig. 1b; also see Supplementary Fig. S1 online). BLBD-3 and BLBD-6 share a common sequence in the activation region of the $\beta$-catenin/LEF- 1 binding domain (ATDEMIPF); thus, we mutated the activation region (GTDEAAAA, TAT-NLS-BLBD-6m) and found that TAT-NLS-BLBD-6m did not affect the growth of breast cancer cells compared with TAT-NLS-BLBD-6 (Fig. 1b). Therefore, the activation region sequence (ATDEMIPF) is responsible for the growth inhibition of human breast cancer cells.

Next, we analyzed the time and dose dependence of TAT-NLS-BLBD-6 on cell growth. The results indicated that TAT-NLS-BLBD-6 inhibited breast cancer cell growth in a time- and dose-dependent manner (Fig. 1c,d). We also examined the effect of combining BLBD- 6 with drugs including E2 $(1 \mu \mathrm{M}), \mathrm{BBP}(1 \mu \mathrm{M})$, and TAM $(1 \mu \mathrm{M})$ with BLBD-6 in breast cancer cells. TAT-NLS-BLBD- 6 blocked the activity of E2 and BBP, but increased the response of TAM in breast cancer cells (Fig. 1e). Interestingly, TAT-NLS-BLBD-6 did not inhibit the growth of human normal mammary epithelial cell H184B5F5/M10 and embryonic kidney 293 (HEK293) cells (Fig. 1f). Together, these results suggested that the ATDEMIPF sequence of TAT-NLS-BLBD-6 inhibits growth of breast cancer cells, but not of normal cells such as H184B5F5/M10 and HEK293.

TAT-NLS-BLBD-6 specifically binds to $\beta$-catenin in the nucleus. Although TAT-NLS-BLBD- 6 inhibited the growth of breast cancer cells, it was not clear whether TAT-NLS-BLBD-6 could enter into the nucleus and bind the $\beta$-catenin elements in vitro. We first determined the subcellular distribution of TAT-NLS-BLBD-6 peptide in the cell. Immunofluorescence staining indicated that TAT-NLS-BLBD-6 $(100 \mu \mathrm{mol} / \mathrm{l})$ was located in the nuclei in both breast cancer cell lines (Fig. 2a). Next, we analyzed the peptide-protein interaction by immunoprecipitation and PLA assay. These assays indicated that TAT-NLS-BLBD- 6 bound to the $\beta$-catenin elements in MCF-7 and MDA-MB-231 cell nuclei (Fig. 2b,c).

TAT-NLS-BLBD-6 induces apoptosis and inhibits invasion, migration, and colony formation. To further investigate the biological effects of these peptides, we evaluated apoptosis, invasion, migration and colony formation. We used flow cytometry and the TUNEL assay to examine the effects of control, TAT-NLS-BLBD-6 and TAT-NLS-BLBD-6m apoptosis. Flow cytometry showed that, compared with control and TAT-NLS-BLBD-6m, TAT-NLS-BLBD-6 increased the sub-G1 phase region (pro-apoptotic effect) from $7.35 \%$ to $37.41 \%$ in MCF-7 and from $18.34 \%$ to $43.10 \%$ in MDA-MB-231 (Fig. 3a). The TUNEL assay showed that TAT-NLS-BLBD- 6 also increased the effect of binding with BrdU and DNA fragmentation when compared with control or TAT-NLS-BLBD-6m in breast cancer cells (Fig. 3b). In addition, invasion, migration and colony-formation assays indicated that TAT-NLS-BLBD-6 inhibited the mobility and proliferation of breast cancer cells when compared with control or TAT-NLS-BLBD-6m (Fig. 3c-e). We used normal cell lines to analyze the phenotypic features of TAT-NLS-BLBD-6. The results revealed that TAT-NLS-BLBD-6 had no effect on the phenotypic features including cell cycles, apoptosis, invasion, migration and colony formation assay in normal cell lines H184B5F5/M10 (Supplementary Fig. S2 online). Therefore, TAT-NLS-BLBD-6 has the potential to mediate biological function in human breast cancer cells.

TAT-NLS-BLBD-6 inhibits tumor growth in the xenograft and xenotransplantation models. To evaluate the effects of the TAT-NLS-BLBD-6 peptides in vivo, we established a xenograft model in nude mice and a zebrafish xenotransplantation model. For the xenograft model, $1 \times 10^{7} \mathrm{MCF}-7$-YFP and MDA-MB-231-GFP cells were subcutaneously injected into the right flanks of nude mice. After 1 week of implantation, the mice were treated with the control, TAT-NLS-BLBD-6m $(1 \mathrm{mg} / \mathrm{kg})$ and TAT-NLS-BLBD-6 ( 1 and $10 \mathrm{mg} / \mathrm{kg}$ ) peptide through intratumoral injection, and the fluorescence density was analyzed by In Vivo Imaging System (IVIS) 35 days after inoculation. TAT-NLS-BLBD-6 inhibited tumor growth without having any effect on body weight when compared with the control peptide (Fig. 4a,b, also see Supplementary Fig. S3 online). In addition, we obtained tumor sections and confirmed that they originated from the injected breast cancer cells, which were positive for YFP or GFP. Immunohistochemistry staining revealed that TAT expression was high and located in the nuclei in the tumors injected with TAT-NLS-BLBD-6 compared with those injected with control peptide (Fig. 4c).

To examine zebrafish xenotransplantation, $1 \times 10^{4}$ MCF-7-GFP and MDA-MB-231-GFP cells were co-injected with TAT-NLS-BLBD-6 or TAT-NLS-BLBD-6m peptide $(100 \mu \mathrm{mol} / \mathrm{l})$ into the yolk sacs of zebrafish embryos. Fluorescence density was captured by fluorescence microscopy at 0, 24 and $48 \mathrm{hr}$ after implantation 
a

BLBD-1 : H-TAT-NLS-ADIKSSLVNESEI-NH ${ }_{2}$ BLBD-2: H-TAT-NLS-DPQKEKIFAEISHPEEEGDL-NH BLBD-3 : H-TAT-NLS-GGGDPELCATDEMIPFKDEG-NH ${ }_{2}$ BLBD-4 : H-TAT-NLS-MPQLSGGGGG-NH ${ }_{2}$ BLBD-5 : H-TAT-NLS-GGGDPELC-NH ${ }_{2}$ BLBD-6 : H-TAT-NLS-ATDEMIPF-NH ${ }_{2}$ BLBD-6m : H-TAT-NLS-GTDEAAAA-NH ${ }_{2}$

C

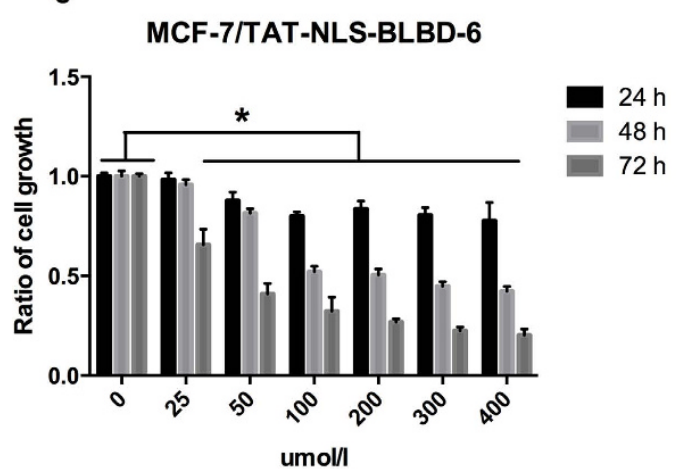

e

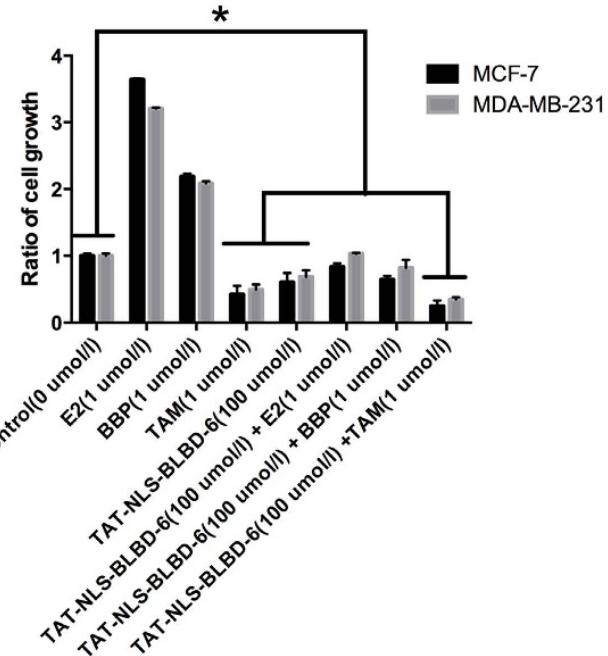

b

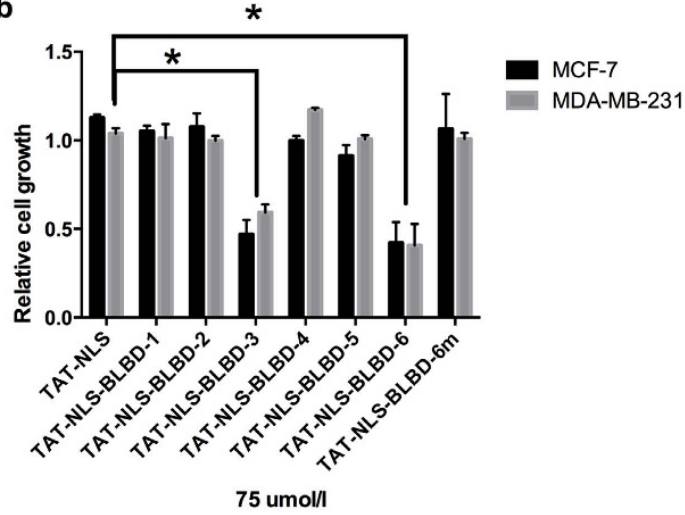

d

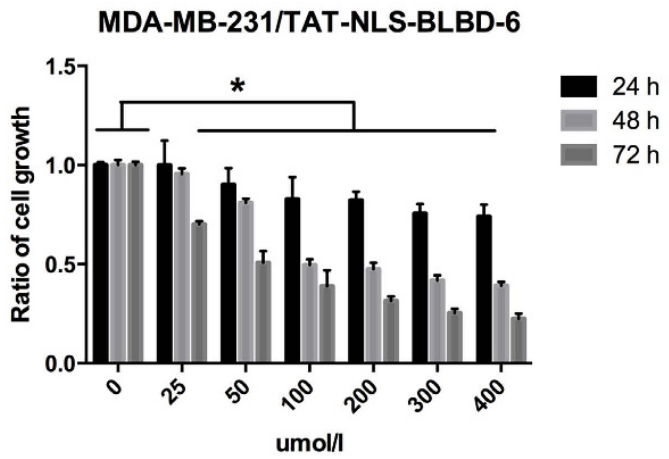

f

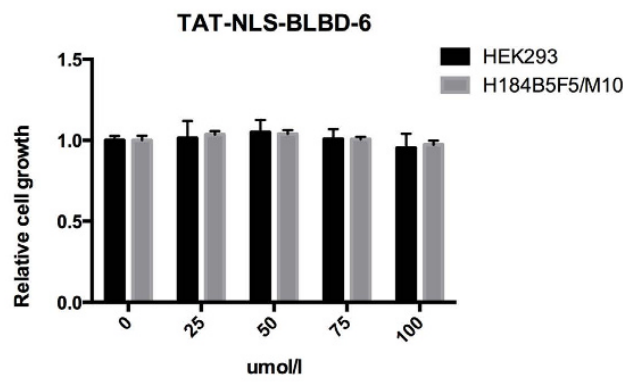

Figure 1. The effect of different BLBD fragments on growth of human breast cancer cells. (a) The seven peptides sequences used in this study. TAT and NLS were linked to six fragments of the $\beta$-catenin binding site on LEF-1 (TAT-NLS-BLBD-1, -2, -3, -4, -5, and -6) (see Supplementary Figure S1 online). TAT-NLS-BLBD-6m was generated by mutating the TAT-NLS-BLBD-6 sequence (red residues). (b) MCF-7 and MDA-MB-231 cells were transfected with $75 \mu \mathrm{mol} / \mathrm{l}$ TAT-NLS-BLBD fragment peptide. (c,d) Cells were transfected with the indicated concentrations of TAT-NLS-BLBD-6 for 24, 48, and $72 \mathrm{hr}$. (e) Cells were treated with E2 $(1 \mu \mathrm{M}), \mathrm{BBP}$ $(1 \mu \mathrm{M})$, TAM $(1 \mu \mathrm{M})$, or a combination of TAT-NLS-BLBD-6 $(100 \mu \mathrm{mol} / \mathrm{l})$ and E2, BBP, or TAM, and the cell growth was evaluated after $48 \mathrm{hr}$. (f) H184B5F5/M10 and HEK293 cells were transfected with the indicated doses of TAT-NLS-BLBD-6 peptide, and cell growth was analyzed by CCK- 8 at $48 \mathrm{hr}$ post-transfection. Data are the means $\pm \mathrm{SD}$ of three experiments. ${ }^{\star} P<0.05 v s$. untreated control; two-tailed Student's $t$ test. Scare bare $=200 \mathrm{uM}$.

(Fig. 5a). The fluorescence density was gradually reduced between $24 \mathrm{hr}$ and $48 \mathrm{hr}$ in the TAT-NLS-BLBD-6 group compared with the TAT-NLS-BLBD-6m group (Fig. 5b,c). Thus, TAT-NLS-BLBD-6 might represent a potential therapeutic strategy to suppress breast tumor growth without toxicity for body weight. 
a

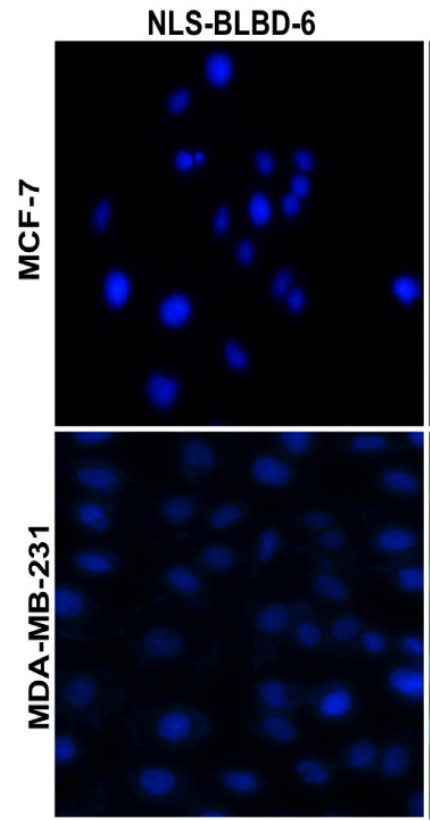

b

TAT-NLS-BLBD-6

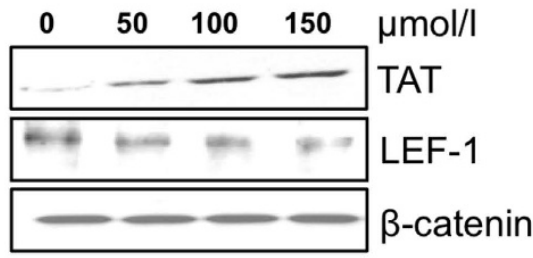

IP: $\beta$-catenin

TAT-NLS-BLBD-6m

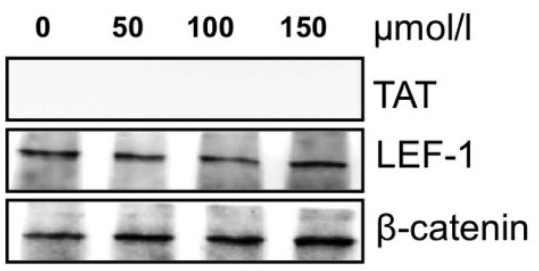

IP: $\beta$-catenin
TAT-BLBD-6
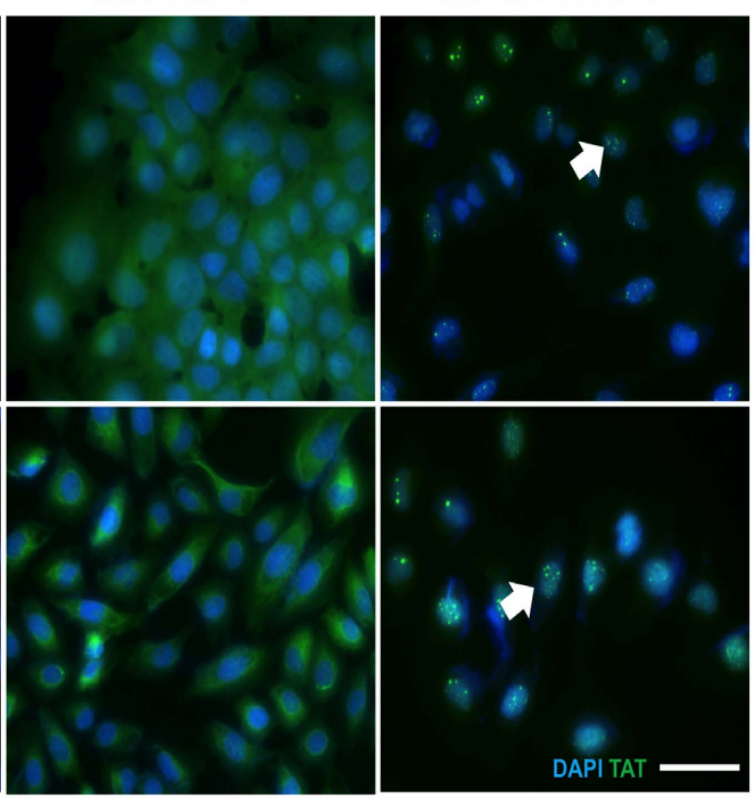

C
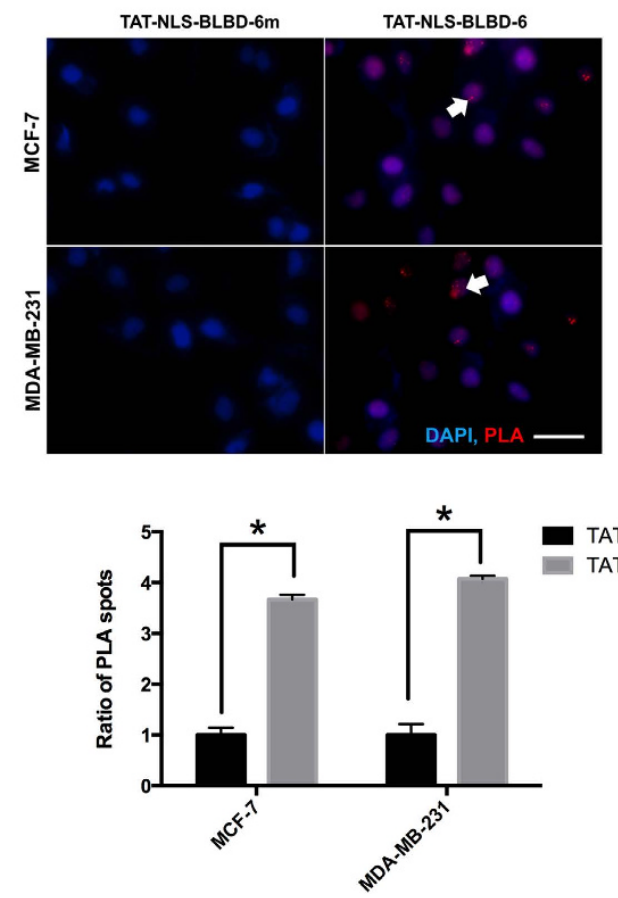

TAT-NLS-BLBD-6m TAT-NLS-BLBD-6

Figure 2. The subcellular distribution and specific binding of TAT-NLS-BLBD-6 in human breast cancer cells. (a) MCF-7 and MDA-MB-231 cells were transfected with $100 \mu \mathrm{mol} / 1$ NLS-BLBD-6, TAT-BLBD-6, or TAT-NLS-BLBD- 6 for $2 \mathrm{hr}$ before washing and fixing. The anti-TAT primary antibody and Alexa- 488 secondary antibody were stained by immunofluorescence, and the fluorescence image was captured by microscopy. Arrows show the TAT-NLS-BLBD-6 peptide distribution in the nucleolus. (b) MCF-7 cells were transfected with the indicated concentrations of TAT-NLS-BLBD-6 and TAT-NLS-BLBD-6m. The protein-protein interaction between TAT and $\beta$-catenin or LEF- 1 and $\beta$-catenin was evaluated by immunoprecipitation with anti- $\beta$-catenin and immunoblotting with the indicated antibodies at $2 \mathrm{hr}$ post-transfection. (c) MCF-7 and MDA-MB-231 cells were transfected with $100 \mu \mathrm{mol} / \mathrm{l}$ TAT-NLS-BLBD-6 or TAT-NLS-BLBD-6m and the protein-protein interaction between TAT and $\beta$-catenin was evaluated by immunofluorescence with the PLA at 2 hr posttransfection. Arrows show the protein-protein interaction in the nucleolus. 
a

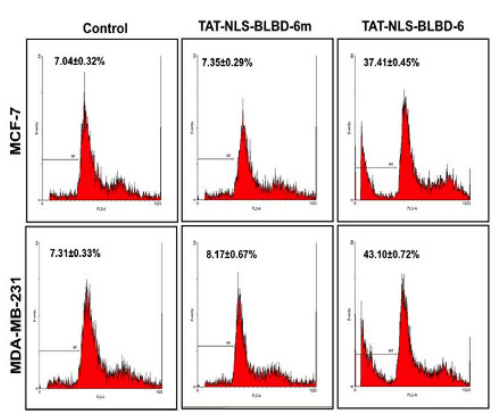

C

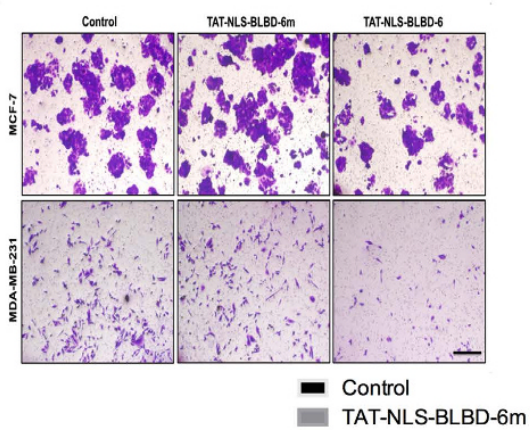

d
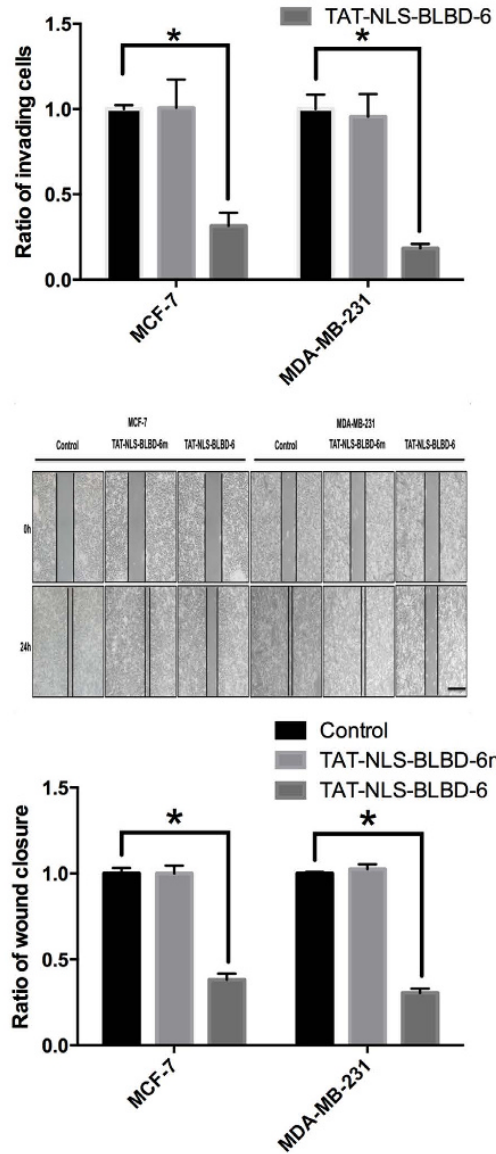

b
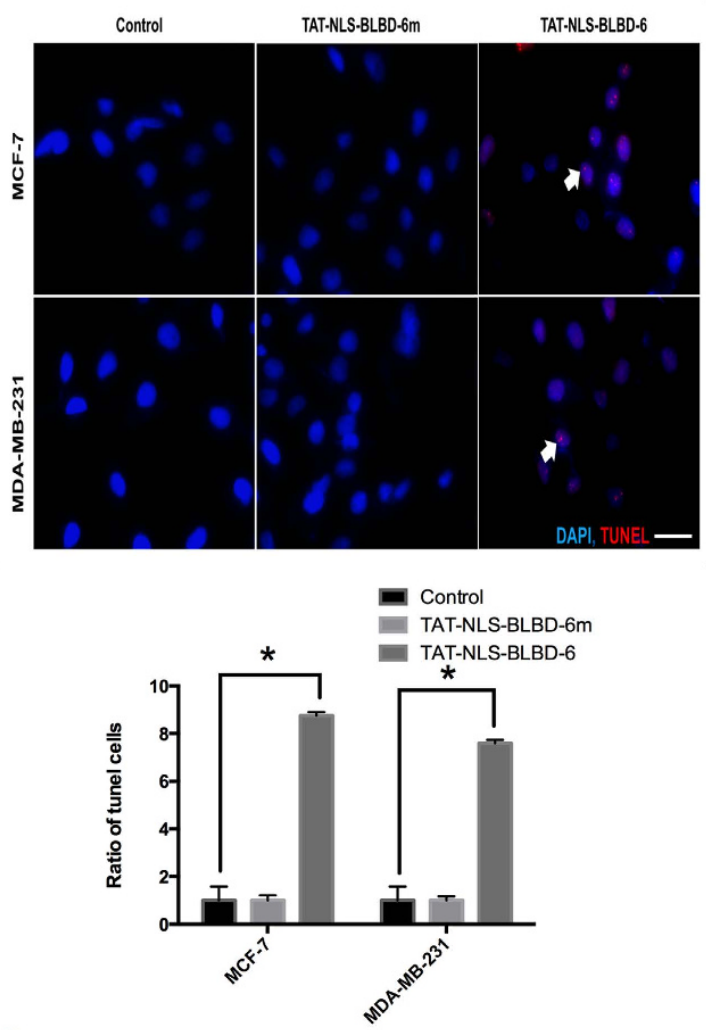

e
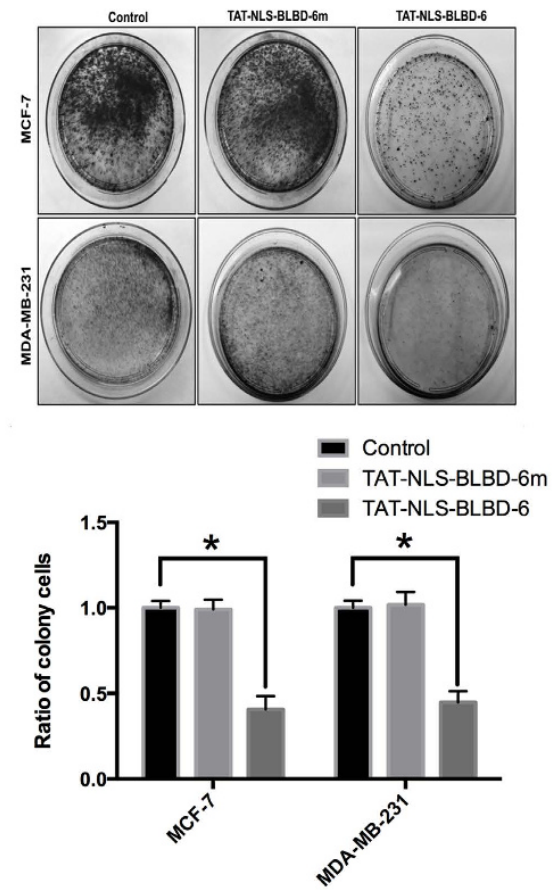

Figure 3. The biological function of TAT-NLS-BLBD-6 in vitro. MCF-7 and MDA-MB-231 cells were transfected with control, $100 \mu \mathrm{mol} / 1$ TAT-NLS-BLBD-6 or TAT-NLS-BLBD-6m. (a) Cell cycle progression was analyzed by propidium iodide staining and flow cytometry. (b) Apoptosis was analyzed by the TUNEL assay. Arrows show apoptosis in the nucleolus. Motility was analyzed by the invasion assay (c) and wound-healing assay $(\mathbf{d})$ at $48 \mathrm{hr}$ post-transfection. Data are the means $\pm \mathrm{SD}$ of three experiments. ${ }^{\star} P<0.05 v s$. untreated control; two-tailed Student's $t$ test. (e) Cell proliferation was analyzed by the colony-formation assay at 14 day post-transfection. Scare bare $=200 \mathrm{uM}$. 


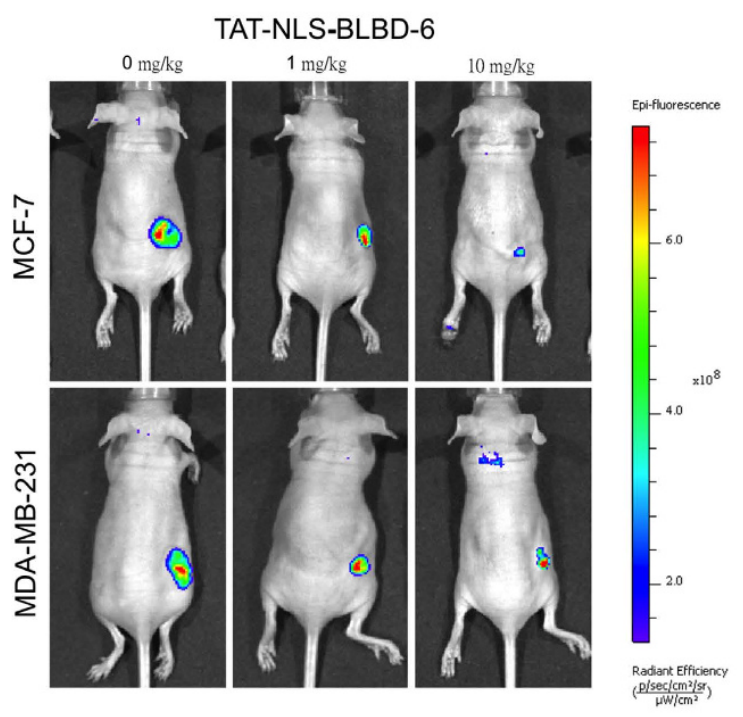

b
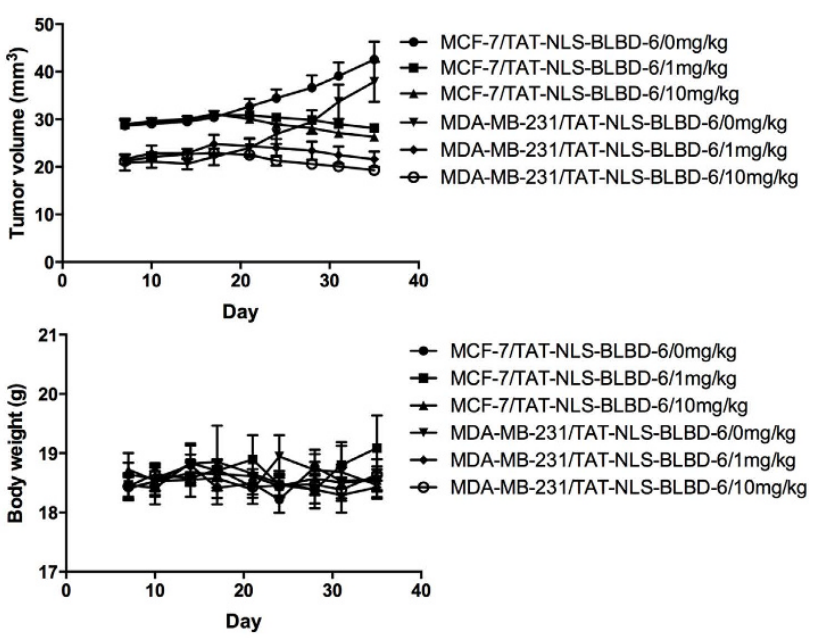

C

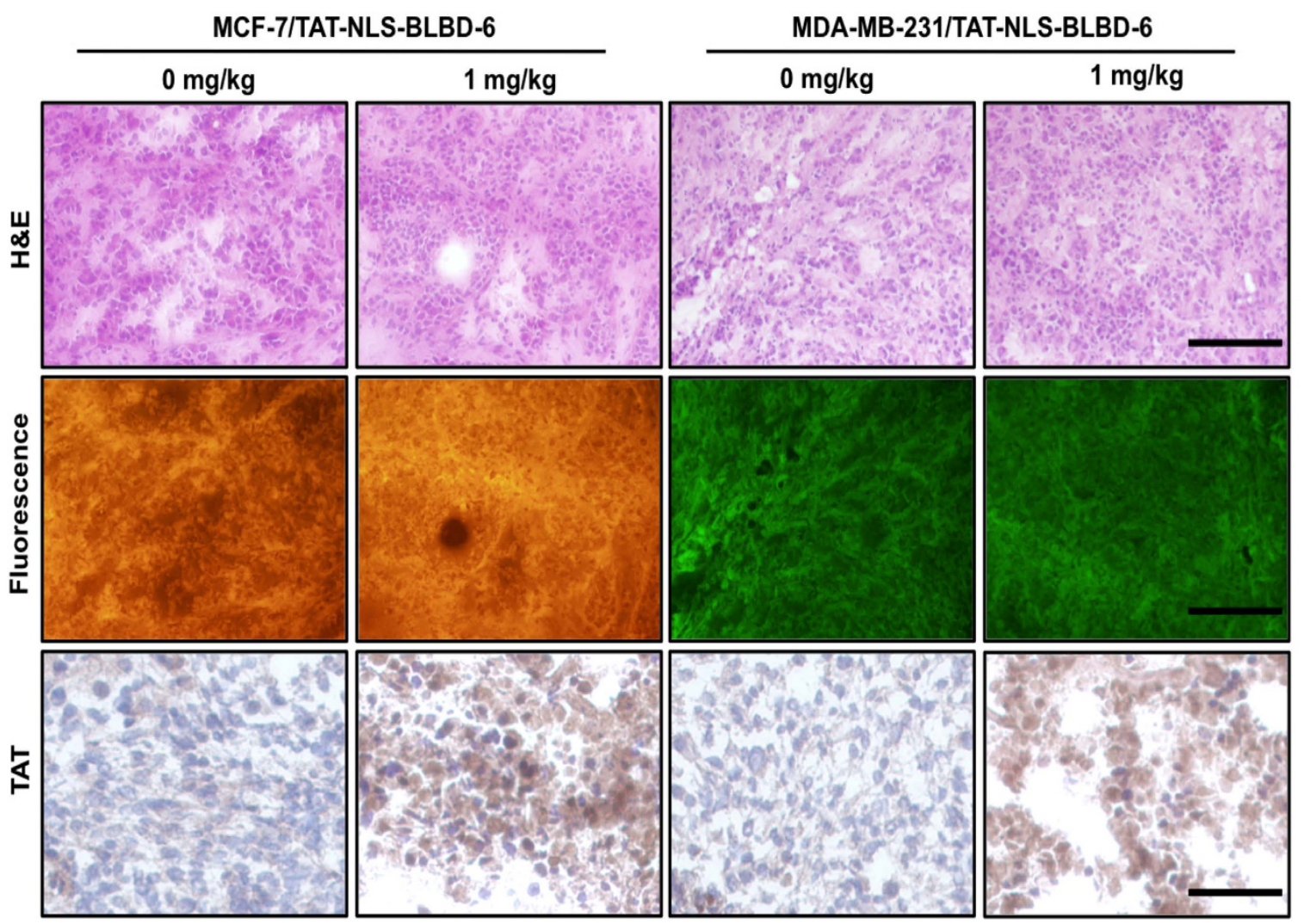

Figure 4. TAT-NLS-BLBD-6 inhibits tumor growth in nude mice. MCF-7-GFP or MDA-MB-231-GFP cells were injected into the right side flanks of SCID nude mice $(\mathrm{n}=5$ per group $)$. The low dose $(1 \mathrm{mg} / \mathrm{kg})$ and high dose $(10 \mathrm{mg} / \mathrm{kg})$ of TAT-NLS-BLBD- 6 were injected into the tumor once every 2 days for 35 days. (a) Tumor GFP images were captured by the IVIS system. (b) The tumor volumes and body weights of nude mice were calculated and recorded. (c) The solid tumor was cut at a thickness of $5 \mu \mathrm{m}$ and examined using hematoxylin and eosin $(\mathrm{H} \& \mathrm{E})$, fluorescence, and immunohistochemistry for TAT staining. Scare bare $=100 \mathrm{uM}$.

profiles of three independent RNA samples from the breast cancer cells treated with TAT-NLS-BLBD-6 and TAT-NLS-BLBD-6m were examined (Fig. 6a). The gene expression profile data were analyzed by Ingenuity Pathway Analysis (IPA) software. The results indicated that 27 genes that were down-regulated in both in 
a

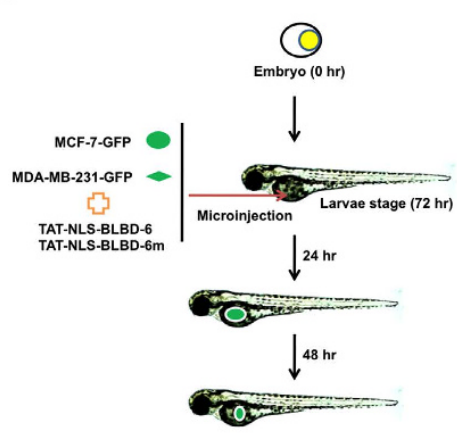

b

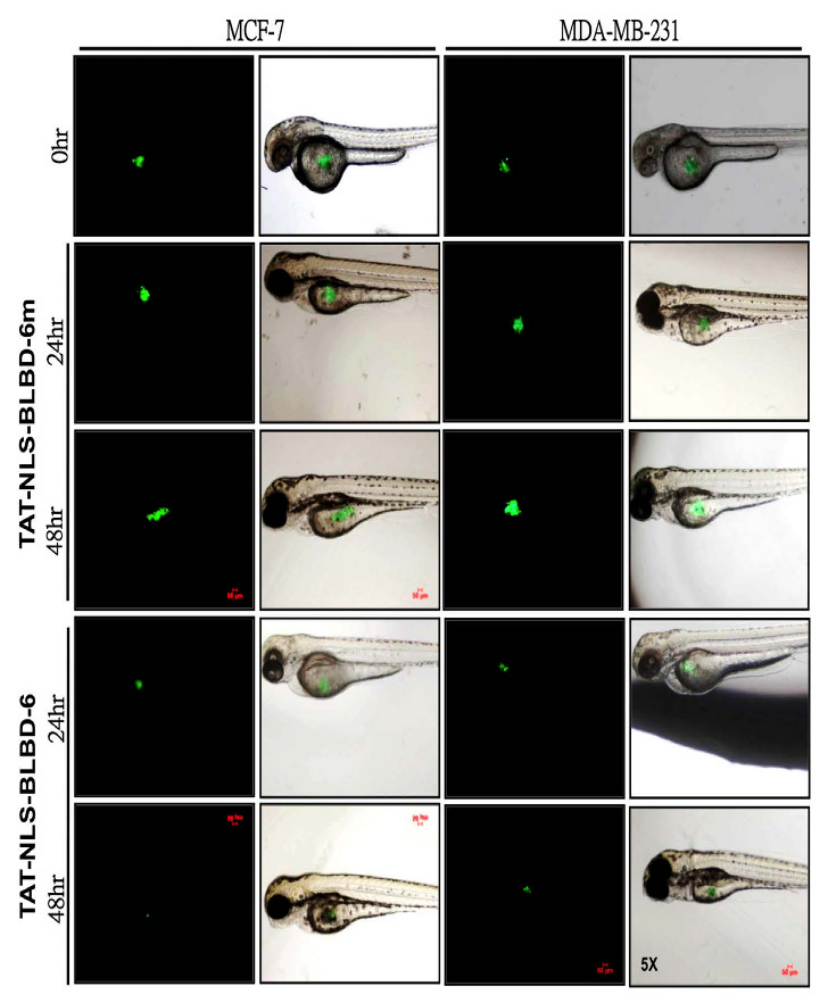

MCF-7

MDA-MB-231 c

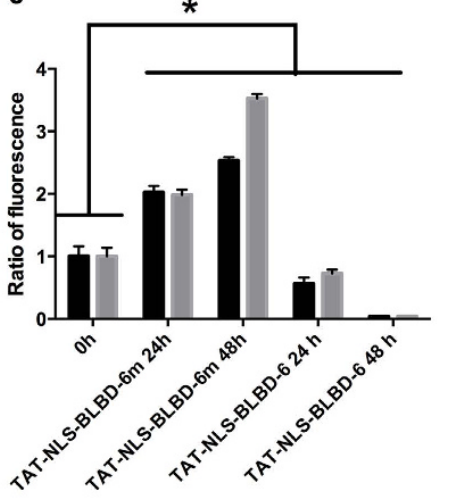

Figure 5. TAT-NLS-BLBD-6 inhibits tumor growth in zebrafish. (a,b) MCF-7-GFP or MDA-MB-231-GFP cells and TAT-NLS-BLBD- 6 were microinjected into the zebrafish embryos (larvae stage, $n=20$ per group). Fluorescence imaging of the whole body of the zebrafish was performed by microscopy $24 \mathrm{hr}$ and $48 \mathrm{hr}$ after transplantation. (c) The photon flux intensity was quantitated by MetaMorph software.

MCF-7 and MDA-MB-231 cells were also identified as $\beta$-catenin/TCF4/LEF-1 downstream genes (Fig. 6b). These genes are BMP4, BTRC, CDKN2A, CLDN1, CLTA4, EDA, EDN1, FGF4, FGF9, FGF18, FOXN1, FST, ID2, IL6, MET, MITF, MYC, MYOG, NANOG, RUNX2, PITX2, SALL4, SOX2, ITAM1, VCAN, VEGFA, and WISP1 (Fig. 6c). Next, we used Q-PCR to confirm the gene expression profile data in breast cancer cells. Indeed, the gene expression of the 27 candidate genes decreased following TAT-NLS-BLBD-6 treatment compared with TAT-NLS-BLBD-6m treatment in MCF-7 (Fig. 6d) and MDA-MB-231 (Fig. 6e) cells. Together, these findings suggest that TAT-NLS-BLBD- 6 can inhibit the expression of $\beta$-catenin/TCF4/LEF downstream genes.

The signaling pathways of down-regulated genes of TAT-NLS-BLBD-6. To further evaluate the pathway maps and molecular and cellular functions of the genes down-regulated by TAT-NLS-BLBD-6, IPA software was used to identify the top two pathways as IL-9 $(p=2.4 \mathrm{E}-02,11.8 \%)$ and HER-2 signaling in breast cancer $(p=3.76 \mathrm{E}-02,7.9 \%)$. Furthermore, the top five functions identified by IPA were lipid metabolism ( $p=3.45 \mathrm{E}-05 \sim 4.84 \mathrm{E}-02)$, molecular transport $(p=3.45 \mathrm{E}-05 \sim 4.84 \mathrm{E}-02)$, small-molecule biochemistry $(p=3.45 \mathrm{E}-05 \sim 4.84 \mathrm{E}-02)$, cellular development ( $p=1.35 \mathrm{E}-04 \sim 4.88 \mathrm{E}-02)$, and cellular growth and proliferation ( $p=1.35 \mathrm{E}-04 \sim 4.81 \mathrm{E}-02)$. To further investigate whether TAT-NLS-BLBD-6 mediated HER-2 signaling pathway, we used one HER2 positive cell line ZR-75-30 to analyze the ability of growth and the gene 
a
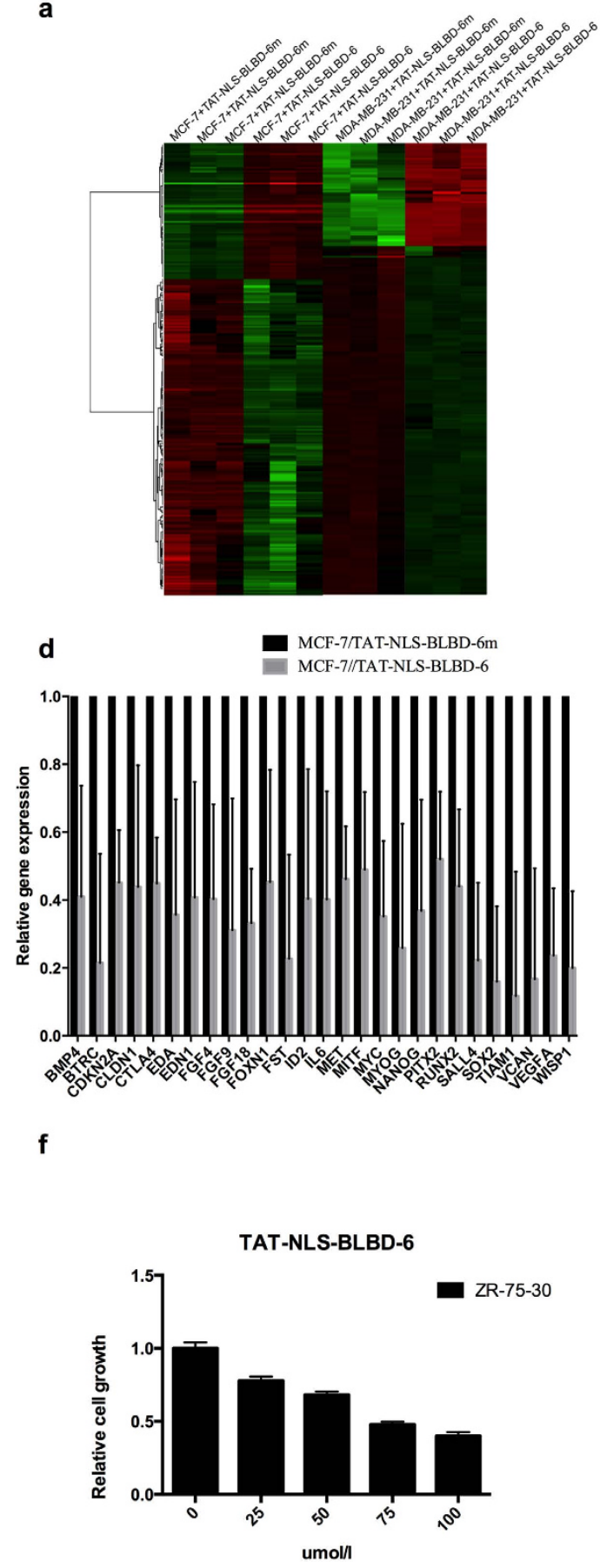

b

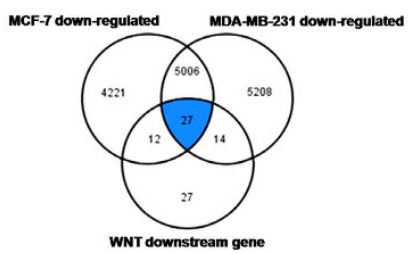

c

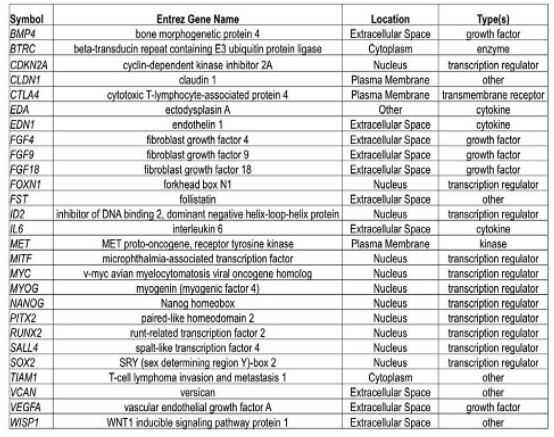

MDA-MB-231/TAT-NLS-BLBD-6m

e MDA-MB-231//TAT-NLS-BLBD-6

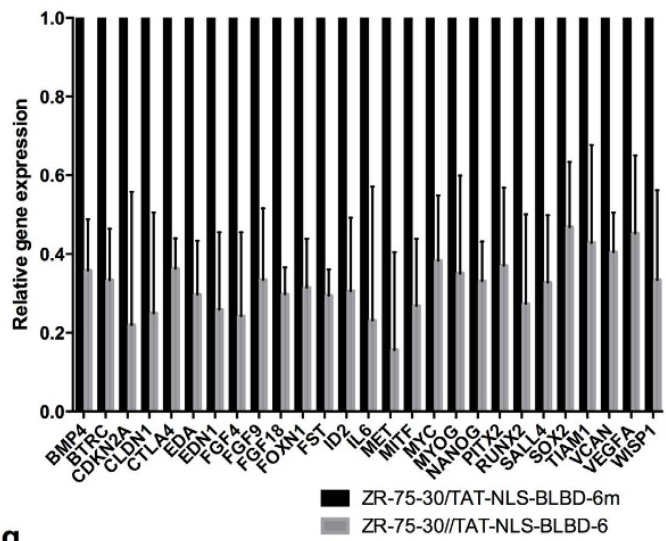

g

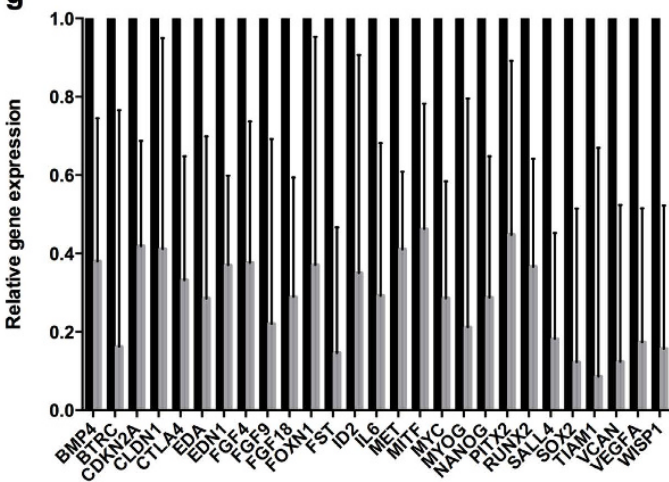

Figure 6. Identifying the downstream target genes of TAT-NLS-BLBD-6. (a) MCF-7 and MDA-MB-231 cells were transfected with $100 \mu \mathrm{mol} / \mathrm{l}$ TAT-NLS-BLBD-6 or TAT-NLS-BLBD-6m. The human global gene expression profiles of three independent RNA samples were analyzed by human oligonucleotide DNA microarray at $48 \mathrm{hr}$ post-transfection. (b,c) Of the genes commonly down-regulated by TAT-NLS-BLBD-6 in MCF-7 and MDA-MB-231, 27 were identical to $\beta$-catenin/TCF4/LEF-1 downstream target genes. (d,e,g) Using Q-PCR, the 27 candidate genes in MCF-7, MDA-MB-231 and ZR-75-30 cells were examined at $48 \mathrm{hr}$ post-transfection with $100 \mu \mathrm{mol} / \mathrm{l}$ TAT-NLS-BLBD- 6 that the expression of each gene is shown relative to the expression in cells transfected with TAT-NLS-BLBD-6m. Data are the means \pm SD of three experiments. (f) ZR-75-30 cells were transfected with control, $100 \mu \mathrm{mol} / \mathrm{l}$ TAT-NLS-BLBD-6 or TAT-NLS-BLBD-6m. Cell growth was analyzed by CCK -8 at $48 \mathrm{hr}$ post-transfection. Data are the means \pm SD of three experiments.

expression of downstream genes when the cells were treated with TAT-NLS-BLBD-6. The results demonstrated that TAT-NLS-BLBD-6 inhibits the growth (Fig. 6f) and the expression of $\beta$-catenin/TCF4/LEF downstream genes (Fig. 6g) in human HER2 positive cell line ZR-75-30. Overall, the IPA software provided evidence that 
TAT-NLS-BLBD-6 may affect inflammatory response, cellular development, and growth and proliferation in human breast cancer (see Supplementary Fig. S4 online).

\section{Discussion}

The Wnt $/ \beta$-catenin signaling pathway regulates the transcription of many genes involved in tumorigenesis and is a potential therapeutic target in cancer progression. Previous reports have shown that Wnt inhibition is a potential therapeutic strategy and can suppress cell growth and invasion in human cancer ${ }^{22,23}$. In our current study, we synthesized a small peptide TAT-NLS-BLBD-6 (ATDEMIPF), which is a Wnt/ $\beta$-catenin signaling inhibitor and prevents the binding of $\beta$-catenin to LEF- 1 at the nuclear region of human breast cancer cells. TAT-NLS-BLBD-6 increased apoptosis and decreased cell growth and motility. Furthermore, we demonstrated that TAT-NLS-BLBD-6 inhibited expression of $27 \beta$-catenin/LEF-1 downstream target genes, including BMP4, BTRC, CDKN2A, CLDN1, CLTA4, EDA, EDN1, FGF4, FGF9, FGF18, FOXN1, FST, ID2, IL6, MET, MITF, MYC, MYOG, NANOG, RUNX2, PITX2, SALL4, SOX2, ITAM1, VCAN, VEGFA, and WISP1. Among these downstream target genes, CDKN2A, CLDN1, CLTA4, IL6, MYC, NANOG, SOX2, VEGFA, and WISP1 are known to be potential prognostic factors and have been considered to be oncogenes in various cancers ${ }^{17,24-30}$.

Various preclinical approaches have been used to inhibit Wnt $/ \beta$-catenin signaling pathways in cancer progression. These modalities, including protein depletion by a neutralizing anti-Dickkopf-1 (DKK1) antibody ${ }^{31}$, the soluble antagonist secreted Frizzled-related protein 2 (sFRP-2) ${ }^{15,32}$, and disheveled PDZ peptides ${ }^{33}$, inhibit tumor growth. Our results found that TAT-NLS-BLBD-6 inhibited cancer cell growth, invasion, and migration in vivo and in vitro, but not in normal cells. Therefore, we believe that using TAT-NLS-BLBD-6 (ATDEMIPF) peptide may be an effective therapeutic approach for human breast cancer without harm to normal cells. Consistent with our finding regarding the role of the interaction binding sequence, $\mathrm{A}_{17} \mathrm{TDEMIPF}_{24}$, structure analysis found that the LEF-1 residues responsible for binding to $\beta$-catenin are Asp19, Met21, Ile22, and Phe $24^{34}$. The ATDEMIPF had the greatest effect on progression of human breast cancer compared with other sequences.

Previous investigations have reported that environmental hormone factors, such as phthalates (e.g., BBP), stimulate breast cancer through activation of the $\mathrm{Wnt} / \beta$-catenin signaling pathway that contributes to tumorigenesis $^{35}$ and epithelial-mesenchymal transition ${ }^{36}$. Phthalates are important in breast cancer progression; they can induce translocation of $\beta$-catenin into the nucleus and activate the response transcription factors LEF-1/ TCF to induce downstream target gene expression. Therefore, developing new drugs to block Wnt/ $\beta$-catenin signaling will inhibit cancer progression induced by phthalates. In the present study, we demonstrated that TAT-NLS-BLBD-6 combined with BBP blocked cell growth induced by BBP. This result suggests that TAT-NLS-BLBD-6 is an inhibitor for breast cancer progression induced by phthalates.

HER- 2 is a tyrosine-protein kinase 2 of the ErbB family ${ }^{37}$. Early study found that the $\beta$-catenin/LEF- 1 was activated by HER- 2 to induce proliferation, invasion and migration and survival of cancer cells ${ }^{38,39}$. In addition, IL-9 is a cytokine produced by T-cells ${ }^{40}$, which was the down-regulated gene of Wnt ${ }^{41}$. Interesting, we results showed that the TAT-NLS-BLBD-6 downstream target genes were associated with IL-9 and HER-2 signaling pathways. This global gene profiles and IPA software results were confirmed with previous study and demonstrate that TAT-NLS-BLBD-6 is an inhibitor of $\beta$-catenin/LEF-1 signaling pathway.

In summary, our study found that TAT-NLS-BLBD-6, a cell-penetrating pentapeptide, blocks the interaction between $\beta$-catenin and LEF- 1 and also efficiently attenuates tumorigenesis in vitro and in vivo. These results suggest that TAT-NLS-BLBD-6 is an effective Wnt signaling inhibitor and may be a potential therapeutic agent of human breast cancer.

\section{Materials and Methods}

Cell culture and peptide synthesis. MCF-7 and MDA-MB-231 cells were purchased from American Type Culture Collection and maintained in DMEM/F12 medium containing 10\% fetal bovine serum and 5\% penicillin-streptomycin-amphotericin (Life Technologies, Grand Island, NY). All cells were incubated at $37^{\circ} \mathrm{C}$ and $5 \% \mathrm{CO}_{2}$. The following peptides were synthesized by Kelowna International Scientific Inc. (Taipei, Taiwan): TAT-NLS-BLBD-1, H-TAT-NLS-ADIKSSLVNESEI-NH ${ }_{2}$; TAT-NLS-BLBD-2, H-TAT-NLSDPQKEKIFAEISHPEEEGDL-NH ${ }_{2}$ TAT-NLS-BLBD-3, H-TAT-NLS-GGGDPELCATDEMIPFKDEG-NH TAT-NLS-BLBD-4, H-TAT-NLS-MPQLSGGGGG-NH ${ }_{2}$; TAT-NLS-BLBD-5, H-TAT-NLS-GGGDPELC-NH ${ }_{2}$; TAT-NLS-BLBD-6, H-TAT-NLS-ATDEMIPF-NH ${ }_{2}$; BLBD-6m, H-TAT-NLS-GTDEAAAA-NH ${ }_{2}$; TAT-BLBD-6, H-TAT-ATDEMIPF-NH ${ }_{2}$; NLS-BLBD-6, H-NLS-ATDEMIPF-NH ${ }_{2}$

Cell growth. Cell growth was analyzed using 2-(2-methoxy-4-nitrophenyl)-3-(4-nitroph enyl)-5(2,4-disulfophenyl)-2H-tetrazolium, monosodium salt, and the Cell Counting Kit-8 (CCK-8, Sigma). MCF7, MDA-MB-231, and HEK293 cells were seeded in 96-well plates and incubated with peptide BLBD1-6, $17 \beta$-estradiol (E2, $1 \mu \mathrm{M})$, benzyl butyl phthalate (BBP, $1 \mu \mathrm{M})$, and tamoxifen (TAM, $1 \mu \mathrm{M})$. After culturing for another $48 \mathrm{hr}$, cell growth was analyzed by CCK- 8 and the optical density was detected at $450 \mathrm{~nm}$. The growth ratio was normalized to the cells without treatment.

Immunoprecipitation and western blotting. Immunoprecipitation and western blotting were performed as described previously ${ }^{42,43}$. MCF-7 and MDA-MB-231 cells were harvested in $4{ }^{\circ} \mathrm{C}$ phosphate-buffered saline and cell pellets were lysed with RIPA lysis buffer (Millipore, Bedford, MA, USA) for 30 min on ice. Cell lysis supernatant liquid was obtained by centrifugation at $10,000 \times g$ for $10 \mathrm{~min}$, incubated with protein-G beads (Roche, Indianapolis, IN) and anti- $\beta$-catenin, and subjected to western blotting. For the western blotting assay, cellular extract proteins were separated by SDS-polyacrylamide gel (SDS-PAGE) and transferred to nitrocellulose membrane (Millipore) using a dry transfer apparatus (Bio-Rad). After blocking nonspecific binding with 5\% 
milk buffer, the membrane was incubated with primary antibodies: anti-TAT (Santa Cruz Biotechnology, Santa Cruz, CA, USA), anti-LEF-1(Epitomics, Burlingame, CA, USA) and anti- $\beta$-catenin (Epitomics, Burlingame, CA, USA). The proteins were visualized using ECL (Amersham Pharmacia Biotech) and coupled using the Bio-Rad Chemiluminescent Detection System.

Immunofluorescence, TUNEL staining, and proximity ligation assay (PLA). MCF-7 and MDA-MB-231 cells were cultured in 35-mm plates with cover slides on the plate bottom and treated with NLS-BLBD-6, TAT-BLBD-6 and TAT-NLS-BLBD-6 peptide for $24 \mathrm{hr}$. Subsequently, cells were fixed with $4 \%$ paraformaldehyde and permeabilized with $0.2 \%$ Triton X-100 for $20 \mathrm{~min}$ at room temperature. For the immunofluorescence assay, the slides were incubated with primary antibodies, anti- $\beta$-catenin (Epitomics) and anti-TAT (Santa Cruz), for $6 \mathrm{hr}$, and Alexa-488 fluorescence secondary antibodies for $1 \mathrm{hr}$. DAPI (Sigma, St Louis, MO) was used to stain the nucleus for $1 \mathrm{~min}$ at room temperature. For the TUNEL assay, apoptosis was analyzed by the Apo-BrdU-red DNA Fragmentation Assay kit, according to the manufacturer's protocol (BioVision, Mountain View, CA, USA). For the PLA, the protein-protein interaction assay was analyzed by Duolink ${ }^{\circledR}$ using PLA ${ }^{\circledR}$ Technology, according to the manufacturer's protocol (Olink Bioscience, Uppsala, Sweden). Briefly, the slides were incubated with primary antibodies, anti- $\beta$-catenin (Epitomics) and anti-TAT (Santa Cruz), and secondary antibodies, Duolink PLA Rabbit MINUS and PLA Mouse PLUS proximity probes. Finally, the proximity ligation was performed by the Duolink detection reagent kit (Olink Bioscience). The immunofluorescence image and TUNEL staining was photographed by a microscope (IX-71, Olympus, Tokyo, Japan).

Cell cycle analysis. MCF-7 and MDA-MB-231 cells were plated in 6-well plates for $24 \mathrm{hr}$, and the medium was replaced with fresh culture medium containing $100 \mu \mathrm{mol} / \mathrm{l}$ peptide. After incubation for $24 \mathrm{hr}$, the cells were harvested by trypsinization and then fixed with $70 \% 4{ }^{\circ} \mathrm{C}$ ethanol. Intracellular DNA was stained with $50 \mathrm{ng} / \mathrm{ml}$ propidium iodide in the dark for $30 \mathrm{~min}$ at room temperature, and the percentages of sub-G1 cells were determined by flow cytometry (BD LSRII analyzer; BD Biosciences).

Invasion, migration, and colony-formation assays. Transwell chambers of 8-mm pore size were used in the in vitro invasion assay. MCF-7 and MDA-MB-231 cells were seeded onto the upper chamber and incubated with TAT-NLS-BLBD- 6 and TAT-NLS-BLBD- $6 \mathrm{~m}$ peptide and $10 \%$ fetal bovine serum medium were added to the bottom chamber well. After $24 \mathrm{hr}$, cells invading the lower chamber were fixed with $4 \%$ paraformaldehyde solution and stained with $0.1 \%$ crystal violet for $30 \mathrm{~min}$ at $37^{\circ} \mathrm{C}$. Three random field images were obtained by microscopy, and the number of invading cells were counted. For the migration assay, MCF-7 and MDA-MB-231 cells were seeded onto 6 -well plates. After $24 \mathrm{hr}$, an artificial wound was created using a $10-\mu \mathrm{l}$ pipette tip, and the wound was incubated with TAT-NLS-BLBD- 6 or TAT-NLS-BLBD- $6 \mathrm{~m}$ for $24 \mathrm{hr}$ at $37^{\circ} \mathrm{C}$. The images of wound healing were captured by microscopy, and the wound healing distances were calculated by Image J (U.S. National Institutes of Health, Bethesda, MD, USA). For the colony formation assay, MCF-7 and MDA-MB-231 cells were seeded into $10-\mathrm{cm}$ dishes with the medium containing TAT-NLS-BLBD-6 or TAT-NLS-BLBD-6m. After 2 weeks, cells were fixed with $4 \%$ paraformaldehyde solution and stained with $0.1 \%$ crystal violet for $30 \mathrm{~min}$ at $37^{\circ} \mathrm{C}$.

Tumor growth analysis in vivo. All animal experiments were approved by the Kaohsiung Medical University Institutional Animal Care and Use Committee (IACUC Approval No: 101156) and we accordance with the approved guidelines. Female nude mice (4-5 weeks old) were obtained from the National Laboratory Animal Center (Taipei, Taiwan). Xenograft tumor models were established by subcutaneous injection of $1 \times 10^{7}$ MCF-7-YFP or MDA-MB-231-GFP cells into the right flanks of mice. Mice with palpable tumors were randomly divided into three groups with five animals in each group. The mice were treated with control peptide, 0,1 and $10 \mathrm{mg} / \mathrm{kg}$ TAT-NLS-BLBD- 6 by intratumoral injection once every 2 days for 35 days. The fluorescence density was analyzed by an In Vivo Imaging System (IVIS) (Berthold Technologies, Bad Wildbad, Germany), and the tumor volumes $(\mathrm{V})$ of nude mice were calculated by: $\mathrm{V}=$ length $\times \operatorname{diameter}^{2} \times 0.5$. For zebrafish xenotransplantation, zebrafishes (Danio rerio) were maintained at $28^{\circ} \mathrm{C}$ in an air incubator, and $1 \times 10^{4} \mathrm{MCF}-7$-GFP or MDA-MB-231-GFP cells combined with TAT-NLS-BLBD- 6 or control peptide were injected into the zebrafish embryos according to the previously described protocol ${ }^{44}$. The fluorescence density was measured 24 and $28 \mathrm{hr}$ after injection using an epifluorescence microscope.

Histologic study of the tumor. Tumor tissues were sectioned to a thickness of $5 \mu \mathrm{m}$ and mounted on microscope slides. Tissue slides were stained with a Dako LSAB kit (Dako, Carpinteria, CA) according to the manufacturer's protocol. The TAT antibody (Santa Cruz) was used for immunohistochemistry, and the nuclei were stained with hematoxylin and eosin. The fluorescence images were captured by a fluorescence microscope (IX-71, Olympus, Tokyo, Japan).

Human oligonucleotide DNA microarray. Total RNA was extracted from cells using the Trizol reagent (Invitrogen, Carlsbad, CA, USA). The RNA concentration and purity were checked by $\mathrm{OD}_{260} / \mathrm{OD}_{280}(>1.8)$ and $\mathrm{OD}_{260} / \mathrm{OD}_{230}(>1.6)$, and the yield and quality were accessed using an Agilent 2100 Bioanalyzer (Agilent Technologies, Santa Clara, CA, USA). The Human Whole Genome OneArray ${ }^{\circledR}$ v6 (Phalanx Biotech Group, Taiwan) contains 32,679 DNA oligonucleotide probes, and each probe is a 60-mer designed in the sense direction. Among the probes, 31,741 probes correspond to the annotated genes in the RefSeq v51 and Ensembl v65 databases. In addition, 938 control probes are also included. The detailed descriptions of the gene array list are available from http://www.phalanx.com.tw/Products/HOA_Probe.php 
Microarray analysis. Fluorescent aRNA targets were prepared from $1 \mu \mathrm{g}$ total RNA samples using the OneArray ${ }^{\circledR}$ Amino Allyl aRNA Amplification kit (Phalanx Biotech Group, Taiwan) and Cy5 dyes (Amersham Pharmacia, Piscataway, NJ, USA). Fluorescent targets were hybridized to the Human Whole Genome OneArray ${ }^{\circledR}$ with Phalanx hybridization buffer using the Phalanx Hybridization System. After $16 \mathrm{hr}$ of hybridization at $50^{\circ} \mathrm{C}$, non-specific binding targets were washed away by three different washing steps (wash I $42^{\circ} \mathrm{C} 5 \mathrm{~min}$; wash II $42^{\circ} \mathrm{C}$, $5 \mathrm{~min}, 25^{\circ} \mathrm{C} 5 \mathrm{~min}$; wash III rinse 20 times), and the slides were dried by centrifugation and scanned by an Agilent G2505C scanner (Agilent Technologies, Santa Clara, CA, USA). The Cy5 fluorescence intensities of each spot were analyzed by GenePix 4.1 software (Molecular Devices). The signal intensity of each spot was loaded into the Rosetta Resolver System ${ }^{\circledR}$ (Rosetta Biosoftware) to process data analysis. The error model of Rosetta Resolver System ${ }^{\circledR}$ could remove both systematic and random errors from the data. We filtered out spots for which the flag was less than 0 . Spots that passed the criteria were normalized by the $50 \%$ media scaling normalization method. The technically repeated data were tested by the Pearson correlation coefficient calculation to check the reproducibility ( $\mathrm{R}$ value $>0.975$ ). Normalized spot intensities were transformed to gene expression $\log _{2}$ ratios between the control and treatment groups. The spots with $\log _{2}$ ratio $\geq 1$ or $\log _{2}$ ratio $\leq-1$ and $P$-value $<0.05$ were tested for further analysis.

Quantitative RT-PCR. Total RNA was isolated by Trizol reagent (Invitrogen, Carlsbad, CA, USA) and reverse transcribed to produce cDNA using the Deoxy + HiSpec reverse transcriptase kit (Yeastern, Taipei, Taiwan) according to the manufacturer instructions. Q-PCR was analyzed with SYBR Green Master Mix (Applied Biosystems, Stockholm, Sweden) and subjected to quantitation in an Applied Biosystems LightCycler instrument. The primers used for PCR are given in Supplementary Table S5 online. The Q-PCR data were normalized to 18S cDNA levels.

\section{References}

1. Torre, L. A. et al. Global cancer statistics, 2012. CA Cancer J Clin 65, 87-108 (2015).

2. Miki, Y. et al. A strong candidate for the breast and ovarian cancer susceptibility gene BRCA1. Science 266, 66-71 (1994).

3. Irwin, M. L. et al. Changes in body fat and weight after a breast cancer diagnosis: influence of demographic, prognostic, and lifestyle factors. J Clin Oncol 23, 774-782 (2005).

4. Coussens, L. M. \& Werb, Z. Inflammation and cancer. Nature 420, 860-867 (2002).

5. Hamajima, N. et al. Alcohol, tobacco and breast cancer-collaborative reanalysis of individual data from 53 epidemiological studies, including 58,515 women with breast cancer and 95,067 women without the disease. Br J Cancer 87, 1234-1245 (2002).

6. Hsieh, T. H. et al. n-Butyl benzyl phthalate promotes breast cancer progression by inducing expression of lymphoid enhancer factor 1. PLoS One 7, e42750 (2012).

7. Fisher, B. et al. Effect of preoperative chemotherapy on the outcome of women with operable breast cancer. J Clin Oncol 16, 2672-2685 (1998).

8. Grigoryan, G., Reinke, A. W. \& Keating, A. E. Design of protein-interaction specificity gives selective bZIP-binding peptides. Nature 458, 859-864 (2009).

9. Frankel, A. E. New HER2-directed therapies for breast cancer. Commentary re: C. I. Spiridon et al. Targeting multiple Her-2 epitopes with monoclonal antibodies results in improved antigrowth activity. Clin. Cancer Res. 8, 1720-1730, 2002. Clin Cancer Res 8, 1699-1701 (2002).

10. Lien, S. \& Lowman, H. B. Therapeutic peptides. Trends Biotechnol 21, 556-562 (2003).

11. Behrens, J. et al. Functional interaction of beta-catenin with the transcription factor LEF-1. Nature 382, 638-642 (1996).

12. Willert, K. et al. Wnt proteins are lipid-modified and can act as stem cell growth factors. Nature 423, 448-452 (2003).

13. Weeraratna, A. T. et al. Wnt5a signaling directly affects cell motility and invasion of metastatic melanoma. Cancer Cell 1, 279-288 (2002).

14. Muller, T., Bain, G., Wang, X. \& Papkoff, J. Regulation of epithelial cell migration and tumor formation by beta-catenin signaling. Exp Cell Res 280, 119-133 (2002).

15. Matsuda, Y. et al. WNT signaling enhances breast cancer cell motility and blockade of the WNT pathway by sFRP1 suppresses MDA-MB-231 xenograft growth. Breast Cancer Res 11, R32 (2009).

16. Guo, D., Huang, J. \& Gong, J. Bone morphogenetic protein 4 (BMP4) is required for migration and invasion of breast cancer. Mol Cell Biochem 363, 179-190 (2012).

17. Berns, E. M. et al. c-myc amplification is a better prognostic factor than HER $2 /$ neu amplification in primary breast cancer. Cancer Res 52, 1107-1113 (1992).

18. Shtutman, M. et al. The cyclin D1 gene is a target of the beta-catenin/LEF-1 pathway. Proc Natl Acad Sci USA 96, 5522-5527 (1999).

19. Nagahara, H. et al. Transduction of full-length TAT fusion proteins into mammalian cells: TAT-p27Kip1 induces cell migration. Nat Med 4, 1449-1452 (1998).

20. Gump, J. M. \& Dowdy, S. F. TAT transduction: the molecular mechanism and therapeutic prospects. Trends Mol Med 13, 443-448 (2007).

21. Clevers, H. Wnt/beta-catenin signaling in development and disease. Cell 127, 469-480 (2006).

22. Tang, Y. et al. WIF1, a Wnt pathway inhibitor, regulates SKP2 and c-myc expression leading to G1 arrest and growth inhibition of human invasive urinary bladder cancer cells. Mol Cancer Ther 8, 458-468 (2009).

23. Shimomura, Y. et al. APCDD1 is a novel Wnt inhibitor mutated in hereditary hypotrichosis simplex. Nature 464, 1043-1047 (2010).

24. Chen, P. P. et al. Expression of Cyr61, CTGF, and WISP-1 correlates with clinical features of lung cancer. PLoS One 2, e534 (2007).

25. Downey, S. G. et al. Prognostic factors related to clinical response in patients with metastatic melanoma treated by CTL-associated antigen-4 blockade. Clin Cancer Res 13, 6681-6688 (2007).

26. Nakashima, J. et al. Serum interleukin 6 as a prognostic factor in patients with prostate cancer. Clin Cancer Res 6, 2702-2706 (2000).

27. Sholl, L. M. et al. Sox 2 protein expression is an independent poor prognostic indicator in stage I lung adenocarcinoma. Am J Surg Pathol 34, 1193-1198 (2010).

28. Kim, M. et al. Homozygous deletion of CDKN2A (p16, p14) and CDKN2B (p15) genes is a poor prognostic factor in adult but not in childhood B-lineage acute lymphoblastic leukemia: a comparative deletion and hypermethylation study. Cancer Genet Cytogenet 195, 59-65 (2009).

29. Meng, H. M. et al. Over-expression of Nanog predicts tumor progression and poor prognosis in colorectal cancer. Cancer Biol Ther 9, 295-302 (2010).

30. Mohammed, R. A. et al. Prognostic significance of vascular endothelial cell growth factors -A, -C and -D in breast cancer and their relationship with angio- and lymphangiogenesis. Br J Cancer 96, 1092-1100 (2007).

31. Sato, N. et al. Wnt inhibitor Dickkopf-1 as a target for passive cancer immunotherapy. Cancer Res 70, 5326-5336 (2010). 
32. Oshima, T. et al. Myeloma cells suppress bone formation by secreting a soluble Wnt inhibitor, sFRP-2. Blood 106, 3160-3165 (2005).

33. Zhang, Y. et al. Inhibition of Wnt signaling by Dishevelled PDZ peptides. Nat Chem Biol 5, 217-219 (2009).

34. Sun, J. \& Weis, W. I. Biochemical and structural characterization of beta-catenin interactions with nonphosphorylated and CK2phosphorylated Lef-1. J Mol Biol 405, 519-530 (2011).

35. Hsieh, T. H. et al. Phthalates induce proliferation and invasiveness of estrogen receptor-negative breast cancer through the AhR/ HDAC6/c-Myc signaling pathway. FASEB J 26, 778-787 (2012).

36. Hsieh, T. H. et al. Phthalates stimulate the epithelial to mesenchymal transition through an HDAC6-dependent mechanism in human breast epithelial stem cells. Toxicol Sci 128, 365-376 (2012).

37. Sergina, N. V. \& Moasser, M. M. The HER family and cancer: emerging molecular mechanisms and therapeutic targets. Trends Mol Med 13, 527-534 (2007).

38. Ciardiello, F. \& Tortora, G. EGFR antagonists in cancer treatment. N Engl J Med 358, 1160-1174 (2008).

39. Wang, S. C. et al. Binding at and transactivation of the COX-2 promoter by nuclear tyrosine kinase receptor ErbB-2. Cancer Cell 6, 251-261 (2004).

40. Hauber, H. P., Bergeron, C. \& Hamid, Q. IL-9 in allergic inflammation. Int Arch Allergy Immunol 134, 79-87 (2004).

41. Lendeckel, U. et al. Modulation of WNT-5A expression by actinonin: linkage of APN to the WNT-pathway? Adv Exp Med Biol 477, 35-41 (2000).

42. Hsieh, T. H. et al. HDAC inhibitors target HDAC5, upregulate microRNA-125a-5p, and induce apoptosis in breast cancer cells. Mol Ther 23, 656-666 (2015).

43. Hsieh, T. H. et al. miR-125a-5p is a prognostic biomarker that targets HDAC4 to suppress breast tumorigenesis. Oncotarget 6, 494-509 (2015).

44. Nicoli, S. \& Presta, M. The zebrafish/tumor xenograft angiogenesis assay. Nat Protoc 2, 2918-2923 (2007).

\section{Acknowledgements}

This work was supported by the Ministry of Science and Technology of Taiwan (grant numbers MOST 104-2314B-037-091 102-2628-B-037-011-MY3 and 102-2632-B-037-001-MY3) and the Kaohsiung Medical University (Hospital) Research Fund "Aim for the Top Universities Grant, grant No. KMU-TP104A02, KMU-TP104E22, KMUH103-10V07 and KMUH103-3R26).

\section{Author Contributions}

T.H.H. and E.M.T. conceived the work. T.H.H., C.Y.H., C.F.T. performed most of the experiments. T.H.H., C.C.C., S.S.L., T.N.W., P.L.K., C.Y.L. and E.M.T. interpreted the experimental data. T.H.H. wrote the manuscript, and E.M.T. edited the manuscript.

\section{Additional Information}

Supplementary information accompanies this paper at http://www.nature.com/srep

Competing financial interests: The authors declare no competing financial interests.

How to cite this article: Hsieh, T.-H. et al. A novel cell-penetrating peptide suppresses breast tumorigenesis by inhibiting $\beta$-catenin/LEF-1 signaling. Sci. Rep. 6, 19156; doi: 10.1038/srep19156 (2016).

(c) (i) This work is licensed under a Creative Commons Attribution 4.0 International License. The images or other third party material in this article are included in the article's Creative Commons license, unless indicated otherwise in the credit line; if the material is not included under the Creative Commons license, users will need to obtain permission from the license holder to reproduce the material. To view a copy of this license, visit http://creativecommons.org/licenses/by/4.0/ 